\title{
A comparative study between manual vacuum aspiration and electronic suction for surgical treatment of abortion
}

\author{
Gira C. Dabhi, Janki M. Pandya*, Twinkle S. Patel, Nimisha J. Chaudhary
}

Department of Obstetrics and Gynecology, AMC MET Medical college, Ahmedabad, Gujarat, India

Received: 11 August 2021

Accepted: 25 August 2021

\section{*Correspondence:}

Dr. Janki M. Pandya,

E-mail: jankihthakkar@gmail.com

Copyright: (c) the author(s), publisher and licensee Medip Academy. This is an open-access article distributed under the terms of the Creative Commons Attribution Non-Commercial License, which permits unrestricted non-commercial use, distribution, and reproduction in any medium, provided the original work is properly cited.

\section{ABSTRACT}

Background: Present study is done to study the safety, efficacy and complications of using manual vacuum aspiration (MVA) for surgical management of first trimester abortion in comparison to electronic suction.

Methods: It is a retrospective observational study conducted in department of obstetrics and gynecology at tertiary care hospital. Out of 100 cases taken, 50 abortions were done by MVA and 50 were terminated by electric suction/vacuum aspiration (EVA).

Results: In this study, majority of the patients were primigravida (60\%). Most of the patients had period of gestation between 7 to 9 weeks (40\%) followed by up to 6 weeks (33\%) in both groups. Time taken for the procedure was less in MVA (5-9 min.) than electronic suction (7-11 min.). In terms of complications, blood loss $\geq 100 \mathrm{ml}$ was more with EVA $(18 \%)$ compared to MVA (6\%). Uterine perforation was seen with EVA (4\%) and none with MVA. As far as success rate is concerned, EVA got $98 \%$ while MVA got $90 \%$. Post-operative hospital stay was less with MVA ( $\leq 12$ hours) than EVA (up to 24 hours). Post-operative pain perception was less with MVA (18\% severe pain) while with EVA, $36 \%$ with severe pain.

Conclusions: Both the evacuation techniques are almost equally effective and safe, still duration; post-operative pain and hospital stay are less with MVA. Success rate is better with EVA.

Keywords: MVA, EVA, Pain, Abortion

\section{INTRODUCTION}

An estimated 41.6 million abortion occur annually and nearly 19 million $(55 \%)$ of them are unsafe globally. ${ }^{1}$ Almost there is one unsafe abortion for every 10 pregnancies or one abortion every 7 live births worldwide. ${ }^{2}$ In India, the statistics of abortions are grossly inadequate, as only legal abortions are reported.10-19 unsafe abortions take place per 1000 women. $^{3}$ The maternal mortality attributed to abortion in India is $12-18 \%$ in different states. Thus, in India, unsafe illegal abortions remain a serious health problem despite liberal laws established since $1^{\text {st }}$ April, 1972 for medical termination of pregnancy. ${ }^{4}$

The world health organization (WHO) recommends the use of suction for abortion as well as treatment of miscarriage during first trimester from the perspective of safety, efficacy, and lower risk of endometrial damage, such as Asherman's syndrome. These guidelines don't recommend the use of dilatation and curettage (D and C). Thus, D and C should be replaced by vacuum aspiration. ${ }^{5}$

Main objective of this study is to examine safety and efficacy of MVA in comparison to EVA for surgical treatment of first trimester abortion.

\section{METHODS}

It is a retrospective observational study carried out at tertiary care institute (L.G. hospital, Ahmedabad) from $1^{\text {st }}$ February 2020 to $31^{\text {st }}$ of January 2021. 
A total 100 pregnant women were included in this study who under-went surgical management of first trimester abortion. From which, MVA was performed on 50 patients and other 50 patients were treated with electronic suction.

\section{Inclusion criteria}

All the patients included in this study were above age of 18 years. The weeks of gestation calculated from last menstrual period (LMP) were not beyond 12 weeks in any of these patients. Thus, only cases with first trimester abortion were included. Pregnancies with singleton fetus were taken in this study.

\section{Exclusion criteria}

First trimester pregnancies which were suspected to be ectopic pregnancy or suspected molar pregnancies were excluded in present study. Cases with presence of acute pelvic infection, uterine fibroid, any bleeding disorder or any structural anomalies of uterus with first trimester abortion were not included in this study. Patients with history of taking any abortifacient drugs were excluded. Suspected or confirmed septic first trimester abortions were not included in this study.

\section{Methodology}

Total 100 cases of pregnant women in the first trimester abortion were include in this study. Demographic data and detailed history were collected including age, religion, residential status, socio-economic status, chief complaint, obstetric and past menstrual history, any contraceptive method taken previously, any medical or surgical history etc. History of taking any medication for termination of pregnancy noted. Hemoglobin estimation, urine examination for albumin and sugar was done. All these data were collected from case records.

\section{Method of abortion}

Cases were randomly chosen which were subjected to vacuum aspiration either by MVA or EVA after taking written and oral informed consent of the procedure and its complications. In cases of un-dilated cervix, tablet misoprostol $400 \mu \mathrm{g}$ was kept per vaginally 3-4 hours prior to surgery. Intravenous anesthesia (15 $\mathrm{mg}$ of pentazocine and $1-1.5 \mathrm{mg}$ of $1 \%$ propofol $/ \mathrm{kg}$ body weight).

In both the groups, the position of the uterus and size of uterine cavity were confirmed by per vaginal examination and probe and sequentially dilated the cervical canal using Hegar's dilators according to gestational age. In electric suction group, a metal cannula was used depending on the gestational age and the uterine contents were suctioned with a pressure of -400 to $-600 \mathrm{mmHg}$, taking care to place the tip of cannula in the middle of uterine cavity and the cannula was moved up and down and rotated within cavity. In MVA, the cervical canal was dilated to the diameter of cannula equivalent to gestational age using a dilator and the cannula was inserted inside the uterine cavity. Subsequently the double valve of the aspirator was closed and vacuum created inside the syringe (approximate pressure is-610 $\mathrm{mmHg}$ ) and the uterine contents were suctioned after connecting with inserted cannula.

Post operatively patients were monitored for any complaint like per vaginal bleeding, abdominal distension, abdominal pain etc. Pain perception of the patient was measured with numerical scale analogue rating from 1-10 by the patient. Patients were discharged after stabilization and no significant complaint were registered by them.

Data gained from this study was analyzed with help of Microsoft excel software.

\section{Ethical approval}

The ethical approval was not required for this study.

\section{Statistical analysis}

The statistical analysis done by Microsoft excel.

\section{RESULTS}

Study participants included 100 pregnant women who underwent surgical treatment of abortion within 12 weeks of pregnancy at our hospital between 1 st of February 2020 to 31 st of January 2021. Among these, 50 patients were included in MVA group and 50 in the electric suction group.

It shows distribution of the patients according to age group. In both the groups, most of the patients belonged to 18-25 years of age group (20 patients in MVA and 19 patients in EVA), while all of the patients (100\%) belonged to lower socio-economic class.

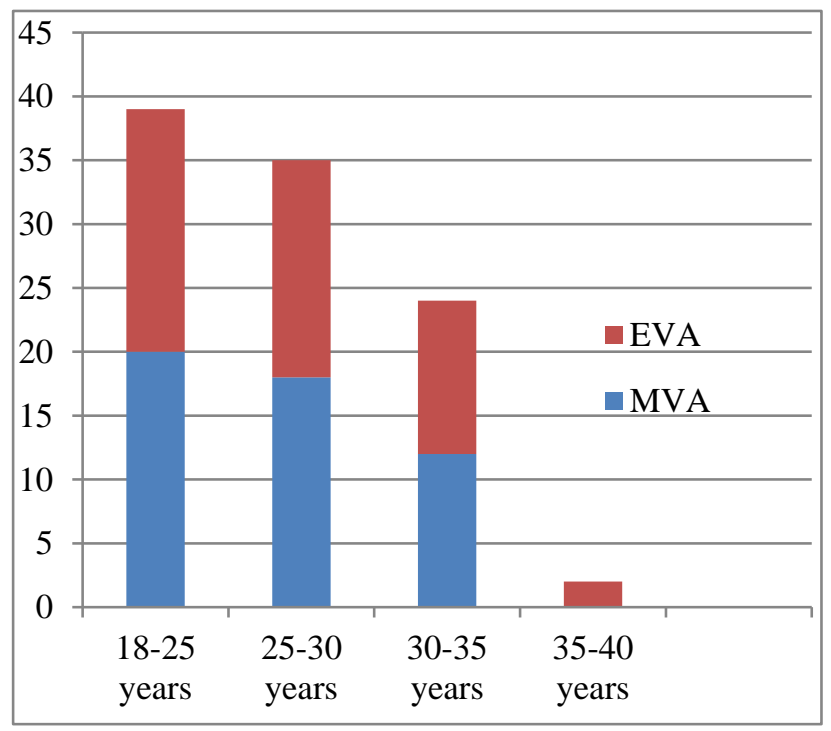

Figure 1: Distribution of patients according to age group. 
In present study, most of the patients were primigravida (60\%). 32 patients (64\%) who underwent MVA and 28 patients $(56 \%)$ who underwent EVA procedures were primigravida whereas 18 patients $(36 \%)$ and 22 patients (44\%) who underwent MVA and EVA respectively were multigravida.

Table 1: Distribution among cases according to gravida.

\begin{tabular}{|lll|}
\hline Gravida & MVA (\%) & EVA (\%) \\
\hline Primigravida & $32(64)$ & $28(56)$ \\
\hline Multigravida & $18(36)$ & $22(44)$ \\
\hline Total & 50 & 50 \\
\hline
\end{tabular}

Most of these patients belonged to 7 to 9 weeks of gestational age in both groups. 21 patients $(42 \%)$ and 19 patients $(38 \%)$ operated by MVA and EVA respectively, which was followed by gestational age group up to 6 weeks 16 patients (32\%) from MVA group and 17 patients $(34 \%)$ from EVA group.

Table 2: Distribution of cases according to gestational age.

\begin{tabular}{|lll|}
$\begin{array}{l}\text { Gestational age } \\
\text { (weeks) }\end{array}$ & MVA $(\%)$ & EVA $(\%)$ \\
\hline$\leq 6$ & $16(32)$ & $17(34)$ \\
\hline $\mathbf{7 - 9}$ & $21(42)$ & $19(38)$ \\
\hline $\mathbf{1 0 - 1 2}$ & $13(26)$ & $14(28)$ \\
\hline Total & 50 & 50 \\
\hline
\end{tabular}

In present study, the time taken for each procedure to be carried out was noted. It showed that duration of the MVA procedure is relatively less than electric suction aspiration procedure. In 36 out of 50 patients (72\%), MVA procedure was carried out in 3 to 7 minutes, while in 14 patients $(28 \%)$ it has taken up to 11 minutes. Whereas, in cases of electric suction, majority of the operation were done within 7 to 11 minutes. [31 patients $(62 \%)$ ]. The procedure was carried out within 7 minutes in 15 patients $(30 \%)$ and in 4 patients $(8 \%)$, it took more than 11 minutes.

Table 3: Comparison of duration of surgery in both of the procedures.

\begin{tabular}{|lll|}
$\begin{array}{l}\text { Duration of } \\
\text { procedure (Min) }\end{array}$ & $\begin{array}{l}\text { MVA } \\
(\mathbf{n = 5 0})(\%)\end{array}$ & $\begin{array}{l}\text { EVA } \\
(\mathbf{n = 5 0})(\%)\end{array}$ \\
\hline $\mathbf{3 - 5}$ & $17(34)$ & $5(10)$ \\
\hline $\mathbf{5 - 7}$ & $19(38)$ & $10(20)$ \\
\hline $\mathbf{7 - 9}$ & $12(24)$ & $18(36)$ \\
\hline $\mathbf{9 - 1 1}$ & $2(4)$ & $13(26)$ \\
\hline $\mathbf{1 1 - 1 3}$ & - & $4(8)$ \\
\hline
\end{tabular}

The results of this study can be comparable to Kakinuma et al study,2020 in which, average time taken for MVA procedure was $6.9 \pm 4.3$ minutes and for EVA procedure, it was $11.2 \pm 4.2$ minutes. $^{6}$
In terms of complications, occurred during and after the suction and vacuum aspiration. There were 3 patients $(6 \%)$ complicated by blood loss of more than $100 \mathrm{ml}$ with MVA, while 9 patients (18\%) were complicated by blood loss of more than $100 \mathrm{ml}$ in case of EVA procedure.

Uterine perforation was seen in 2 cases (4\%) with electric suction, while no case was reported with this complication. While no case was reported with this complication in manual vacuum aspiration.

Incomplete evacuation of the uterus was found with $10 \%$ (5 cases) with MVA procedure while, only 1 case $(2 \%)$ was noted with incomplete evacuation for which repeat procedure is needed. Those after incomplete evacuation with MVA, were followed by electric suction and evacuation.

Other complications like cervical injury, anesthesia complications were not seen with any of the procedures.

Table 4: Comparison of complications in both of the procedures.

\begin{tabular}{|lll|}
\hline Complications & MVA (\%) & EVA (\%) \\
\hline Blood loss $\geq \mathbf{1 0 0} \mathbf{~ m l}$ & $3(6)$ & $9(18)$ \\
\hline $\begin{array}{l}\text { Incomplete } \\
\text { evacuation }\end{array}$ & $5(10)$ & $1(2)$ \\
\hline Uterine perforation & - & $2(4)$ \\
\hline $\begin{array}{l}\text { Anesthesia } \\
\text { complication }\end{array}$ & - & - \\
\hline Cervical injury & - & - \\
\hline
\end{tabular}

Most of the patients, 34 (68\%), were discharged within 12 hours in cases operated by MVA. Whereas only 1 patient (2\%) needed to be hospitalized after 24 hours. In case of electric suction, majority of the patients, 43 (86\%) were needed to be hospitalized for up to 24 hours, only 29 patients $(58 \%)$ were discharged after 12 hours. It can be comparable with data suggested by Tasmin et al, random controlled trial, 2011. It suggested that shorter hospital stay was noted with MVA (12.26 \pm 6.97 hours) than with EVA (19.54 \pm 7.95 hours). ${ }^{7}$

Table 5: Hospital stay after procedures.

\begin{tabular}{|lll|}
$\begin{array}{l}\text { Post-operative } \\
\text { hospital stays } \\
\text { (Hours) }\end{array}$ & $\begin{array}{l}\text { MVA } \\
(\mathbf{n = 5 0})(\%)\end{array}$ & $\begin{array}{l}\text { EVA } \\
(\mathbf{n}=50)(\%)\end{array}$ \\
\hline $\mathbf{6 - 1 2}$ & $34(68)$ & $13(26)$ \\
\hline $\mathbf{1 2 - 1 8}$ & $10(20)$ & $16(32)$ \\
\hline $\mathbf{1 8 - 2 4}$ & $5(10)$ & $14(28)$ \\
\hline $\mathbf{2 4}$ & $1(2)$ & $7(14)$ \\
\hline
\end{tabular}

In study of pain perception, 29 patients (58\%) had complained of moderate pain while 9 patients $(18 \%)$ complained of severe pain, while in EVA procedure, 23 patients $(46 \%)$ were with complaint of moderate pain and 19 patients $(36 \%)$ complained of severe pain. 
Table 6: Comparison of pain perception.

\begin{tabular}{|lll|}
$\begin{array}{l}\text { Post-operative pain } \\
\text { perception (according } \\
\text { to numeric scale 1-10) }\end{array}$ & $\begin{array}{l}\text { MVA } \\
(\mathbf{n}=\mathbf{5 0})(\%)\end{array}$ & $\begin{array}{l}\text { EVA } \\
(\mathbf{n}=50)(\%)\end{array}$ \\
\hline $\begin{array}{l}\text { 1-4 (Mild) } \\
\text { 4-6 (Moderate) }\end{array}$ & $12(24)$ & $8(16)$ \\
\hline $\mathbf{7 - 1}$ (Severe) & $9(18)$ & $23(46)$ \\
\hline
\end{tabular}

\section{DISCUSSION}

Unsafe abortion is a stress to society of India due to large number of women lacking proper education and not desiring contraceptive advises or safer practice is not delivered to them. Thus, there is a need for safe, cost effective, easy to learn and convenient procedure. In this study, maximum numbers of patients were belonged to age group of 18-25 years and primigravida group. In the present study, maximum patients in both the groups had uterus size of 7 to 9 weeks (42\% in MVA and 38\% in EVA) followed by up to 6 weeks ( $32 \%$ in MVA group and $34 \%$ in EVA group) which is comparable to study done by Dutta et al. ${ }^{8}$

Time period taken by MVA procedure is also lesser than with EVA procedure, as with MVA, $72 \%$ of the cases were operated within 7 minutes while with electric suction, in majority of the cases $(62 \%)$ it took 7 to 11 minutes. That is comparable to Kakinuma et al study. ${ }^{6}$

MVA was found safer in this study, as the complications were lesser than with electric suction. Complication of blood loss more than $100 \mathrm{ml}$ was seen in $6 \%$ of cases with MVA comparing to $18 \%$ cases of EVA. Uterine perforation was seen only with electric suction (4\%) and not with MVA. In 5 cases MVA had to be converted in to EVA due to incompleteness and bleeding while in 1 case treated with EVA, incomplete evacuation of uterine cavity was associated, which required repeat procedure.

Success rate of these procedures were calculated depending upon numbers of the cases undergoing reaspiration for incomplete evacuation. Thus, MVA showed $90 \%$ of success rate while EVA showed $98 \%$ of success rate which is comparable to study done by Dutta et al in $2018 .^{8}$

MVA is associated with shorter hospital stay as $68 \%$ of the patients were discharged within 12 hours, whereas only 1 patient $(2 \%)$ needed to be hospitalized after 24 hours. In case of electric suction, majority of the patients, $86 \%$ were needed to be hospitalized for up to 24 hours, only $58 \%$ of patients were discharged after 12 hours. It can be comparable with data suggested by Tasmin et al, random controlled trial, 2011. It suggested that shorter hospital stay was noted with MVA (12.26 \pm 6.97 hours) than with EVA (19.54 \pm 7.95 hours $)^{7}$

In studying pain perception by these patients operated by MVA and EVA, less severe pain perception was seen with
MVA procedure. $18 \%$ with MVA procedure felt severe pain, while with EVA procedure, $36 \%$ of the patients felt severe pain. These findings are comparable to done by Tasnim et al in 2011 and by Wen et al in 2008. ${ }^{7,9}$

Limitation of this study was the patients included here were all from lower socio-economic class and as numerical scale was used for measuring pain perception by patients, pain sensitivity could be different for patients. Another limitation is only small numbers of patients were included in present study.

\section{CONCLUSION}

Surgical treatment for first trimester abortion using the MVA kit is as effective, safe and reliable method as electric suction.

\section{ACKNOWLEDGMENTS}

Author would like to thank Dr. Dipti Shah madam, dean and professor of obstetrics and gynecology, AMC MET medical college, Ahmedabad. Also, to Dr. Munjal Pandya, assistant professor, AMC MET medical college, Ahmedabad.

\section{Funding: No funding sources Conflict of interest: None declared \\ Ethical approval: The study was approved by the Institutional Ethics Committee}

\section{REFERENCES}

1. Abortion Worldwide: A Decade of Uneven Progress. Guttmacher Institute. 2009;17.

2. WHO. Unsafe Abortion: Global and Regional Estimates of the Incidence of Unsafe Abortion and Associated Mortality in 2003. 2003;14. Available at: https://www.who.int/reproductivehealth/publications /unsafe_abortion/9789241596121/en/. Accessed on 3 June 2021.

3. Department of Reproductive Health and Research, World Health Organization. Unsafe abortion; global and regional estimates of the incidence of unsafe abortion and associated mortality. 2008;6. Available at: https://www.who.int/reproductivehealth/ publications/unsafe_abortion/9789241501118/en/. Accessed on 3 June 2021.

4. Park K. Park's textbook of preventive and social medicine. 21st Edn. New Delhi: Banarasidas Bhanot. 2011;468.

5. World Health Organization. Department of Reproductive Health and Research, Safe abortion: technical and policy guidance for health systems Second edition. 2012. http://www.who.int/reproductivehealth/publications/ unsafe_abortion/9789241548434/en/. Accessed 01 August, 2021.

6. Kakinuma T, Kakinuma K, Yukka S, Yoshimasha K, Koyomi S, Motomasha I et al. Safety and efficacy of 
manual vacuum suction compared with conventional dilatation and sharp curettage and electric vacuum aspiration in surgical treatment of miscarriage: a randomized control trial. BMC Pregnancy and Child birth. 2020;20:695.

7. Tasmin N, Mahmud G, Fatima S, Sultana M. Manual vacuum aspiration: a safe and cost- effective substitute of electric vacuum aspiration for the surgical management of early pregnancy loss. J Pak Med Assoc. 2011;61(2):149-53.

8. Dutta BK, Samantha S. A comparative study between manual vacuum aspiration and electrical suction in first trimester MTP. New J OBGYN. 2018;4(2):1547.

9. Wen J, Cai QY, Deng F, Li YP. Manual versus electric vacuum aspiration for first trimester abortion: a systemic review. BJOG. 2008;115(1):5-13.

Cite this article as: Dabhi GC, Pandya JM, Patel TS, Chaudhary NJ. A comparative study between manual vacuum aspiration and electronic suction for surgical treatment of abortion. Int J Reprod Contracept Obstet Gynecol 2021;10:3342-6. 